\title{
Planos nutricionais com a utilização de aminoácidos e fitase para frangos de corte mantendo o conceito de proteína ideal nas dietas ${ }^{1}$
}

\author{
Elisangela Minati Gomide ${ }^{2}$, Paulo Borges Rodrigues ${ }^{3}$, Rilke Tadeu Fonseca de Freitas ${ }^{3}$, \\ Elias Tadeu Fialho ${ }^{3}$
}

\footnotetext{
1 Parte da dissertação de Mestrado da primeira autora. Projeto financiado pelo CNPq.

2 Programa de Doutorado em Zootecnia - UFLA.

${ }^{3}$ Departamento de Zootecnia - UFLA. Bolsista do CNPq.
}

RESUMO - Objetivou-se neste estudo avaliar o desempenho e as características de carcaça de frangos de corte, recebendo rações com níveis reduzidos de PB, P disponível (Pd) e Ca, suplementadas com fitase e aminoácidos. As fases de crescimento avaliadas foram: fase 1, 1 - 21dias de idade e fase 2, 22 - 42 dias de idade. O delineamento experimental foi inteiramente casualizado, sendo os tratamentos constituídos de cincos planos nutricionais (PN), com seis repetições de 25 aves cada. Os planos nutricionais são: PN1 - ração basal (21,4\% PB - fase 1) + ração basal (19,3\% PB - fase 2); PN2 - ração a basal (fase 1) + ração com 18\% PB (fase 2); PN3 - ração basal (fase 1) + ração com 16\% PB (fase 2); PN4 - ração com 19\% PB (fase 1) + ração com 16\% PB (fase 2); e PN5 = ração com 17 \% PB (fase 1) + ração com 16\% PB (fase 2). Exceto para a ração basal, reduziu-se o nível de Pd para 0,34 e 0,30\% e o de Ca para 0,80 e 0,70\% nas fases 1 e 2, respectivamente; nestas rações foram adicionados $500 \mathrm{FTU}$ de fitase/kg de ração. As aves alimentadas com PN2 e PN3 apresentaram desempenho semelhante ao daquelas que receberam PN1, enquanto o das aves que receberam os PN4 e PN5 permaneceu inalterado. Os rendimentos de carcaça e peito não foram influenciados pelos planos nutricionais. As aves que consumiram a ração basal nas duas fases de criação (PN1) apresentaram maior rendimento de coxa+sobre-coxa. Houve aumento da gordura abdominal quando as aves receberam os PN3, 4 e 5. É possível reduzir a PB da ração até 16\% na fase 2, suplementada com fitase e aminoácidos, desde que a ração da primeira fase seja formulada com níveis nutricionais recomendados.

Palavras-chave: características de carcaça, desempenho, enzima, níveis nutricionais

\section{Nutritional plans with use of amino acids and phytase for broiler chickens maintaining the ideal protein profile in the diets}

\begin{abstract}
This study was carried out to evaluate the performance and characteristics of carcass of broiler chickens fed diets with reduced levels of CP, available P (aP) and Ca, supplemented with phytase and amino acids. The growth phases evaluated were: Phase1, 1 - 21 days old, phase 2, 22 - 42 days old. A completely randomized design was used, with the treatments constituted of five nutritional plans (NP), with six replicates of 25 birds each. The nutritional plans were: NP1 - basal ration (21.4\% CP - phase 1) + basal ration (19.3\% CP - phase 2); NP2 = basal ration (phase 1) + ration with 18\% CP (phase 2) NP3 = basal ration (phase 1) + ration with 16\% CP (phase 2); NP4 = ration with 19\% CP (phase 1) + ration with $16 \%$ CP (phase 2) and NP5 = ration with 17\% CP (phase 1) + ration with 16\% CP (phase 2). Except for basal ration, it was reduced the level of aP for $0.34 \%$ and $0.30 \%$ in the phases 1 an 2, respectively, and Ca to 0.80 and $0.70 \%$ in the phases 1 and 2 , respectively, and in theses diets were added 500 FTU of phytase/ kg of ration. The NP4 and NP5 affected the bird performance. The bird fed NP2 and NP3 showed performance similar to those which was fed NP1, while birds that were fed PN4 and PN5 remained unchanged. The carcass and breast yield were not influenced by the nutritional plans. The birds fed basal diets in the two rearing phases (NP1) showed higher yield of thigh + drumstick. There was increase of the abdominal fat when the birds were fed NP3, 4 and 5. In conclusion, is possible to reduce the protein of the ration up to $16 \%$ in the phase 2 , supplemented with phytase and amino acids, since the ration of the phase 1 be formulated with recommended nutritional levels.
\end{abstract}

Key Words: carcass characteristics, enzyme, nutrition levels, performance

\section{Introdução}

Durante muitos anos, a formulação de rações para aves baseou-se no conceito de PB (quantidade de $\mathrm{N} \mathrm{x}$
6,25), o que gerou inúmeros debates nas áreas científica e comercial. Este fato ressalta a evidência de que rações formuladas com base neste conceito resultam em dietas com quantidades de aminoácidos superiores às neces- 
sidades reais dos animais, ocasionando aumento na excreção de nitrogênio e nos custos de produção. Com a disponibilidade de alguns aminoácidos sintéticos produzidos em escala comercial, é possível formular rações com níveis reduzidos de $\mathrm{PB}$, pois possíveis deficiências em aminoácidos, em virtude da redução do nível protéico, podem ser corrigidas com a inclusão desses aminoácidos. Porém, ainda não está evidente até que ponto se pode reduzir o nível protéico da ração e quais aminoácidos devem ser suplementados, sem afetar o desempenho e as características de carcaça de frangos de corte.

Apesar do grande número de estudos realizados avaliando dietas com níveis reduzidos de proteína bruta, há controvérsias quanto aos resultados. Segundo alguns autores, a redução protéica das dietas suplementadas com aminoácidos sintéticos para frangos de corte acarreta diminuição no desempenho das aves (Pinchasov et al.,1990; Costa et al., 2001; Bregendahl et al., 2002). Entretanto, outros autores relatam ser possível reduzir o nível protéico da ração, sem afetar o desempenho das aves, quando suplementadas com aminoácidos (Han et al., 1992; Nagata et al., 2005 a,b; Silva, 2004).

Além da redução do nível de nitrogênio das excretas, os nutricionistas da área animal também têm se preocupado em diminuir a carga poluente do P proveniente das excretas. As rações para aves são constituídas principalmente de alimentos de origem vegetal, que apresentam parte do teor de P na forma do complexo orgânico fitato, que não é aproveitado pelas aves, as quais não sintetizam a enzima fitase. O fitato é um fator antinuticional que diminui significativamente a disponibilidade de $\mathrm{P} \mathrm{e}$ outros nutrientes para os monogástricos. Diversos estudos têm demonstrado que esses efeitos podem ser amenizados com a utilização de enzimas exógenas, como a fitase, capaz de hidrolisar o P fítico, liberando o P e outros nutrientes (Lan et al., 2002; Viveiros et al., 2002; Rutherfurd et al., 2004). Desta forma, é possível formular rações com menor quantidade de fontes inorgânicas de P e outros nutrientes. Além disso, a maior disponibilidade dos nutrientes apresenta efeito positivo no desempenho das aves.

Objetivou-se, neste trabalho, avaliar o efeito de planos nutricionais com níveis reduzidos de PB, Pd e Ca, utilizando-se fitase e aminoácidos, sobre o desempenho e as características de carcaça de frangos de corte no período de 1 a 42 dias de idade.

\section{Material e Métodos}

O experimento foi conduzido no Setor de Avicultura do Departamento de Zootecnia da Universidade Federal de Lavras (UFLA), Lavras, MG. Foram utilizados 750 pintos de corte machos, da linhagem Cobb, de um dia de idade, com peso médio inicial de 38,5 g. As aves foram alojadas e distribuídas aleatoriamente em um galpão de alvenaria, dividido em boxes. O piso foi coberto com maravalhas e cada box continha um comedouro tubular, um bebedouro pendular e uma campânula. A ração e a água foram fornecidas à vontade.

A iluminação foi constante durante todo o período experimental (24 horas de luz, entre natural e artificial). Como fonte de luz artificial utilizaram-se lâmpadas incandescentes de $100 \mathrm{~W}$, distribuídas uniformemente por todo o galpão. A temperatura no galpão foi monitorada pelo manejo de cortinas e ventiladores. As temperaturas máxima e mínima no galpão foram registradas diariamente com a utilização de um termohigrógrafo.

O delineamento experimental utilizado foi inteiramente casualizado, em que os tratamentos consistiram de cinco planos nutricionais ( $\mathrm{PN}$ ), com seis repetições de 25 aves por unidade experimental. Os planos nutricionais foram estabelecidos com base nos melhores resultados obtidos por Silva (2004) e Nagata (2005a, b): PN1 = ração basal 21,4\% PB (Fase 1) + ração basal 19,3 \% PB (Fase 2); PN2 = ração basal 21,4 \% PB (Fase 1) + ração com 18\% PB (Fase 2); PN3 = ração basal 21,4 \% PB (Fase 1) + ração com 16\% PB (Fase 2); PN4 = ração com 19\% PB (Fase 1) + ração com 16\% PB (Fase 2) e PN5 = ração com 17 \% PB (Fase 1) + ração com 16\% PB (Fase 2).

As rações basais foram formuladas de acordo com os níveis nutricionais recomendados por Rostagno et al. (2000) e formuladas à base de milho e farelo de soja. Com exceção das rações basais, as demais foram formuladas com base em aminoácidos digestíveis, mantendo-se a relação ideal dos aminoácidos com a lisina (Tabelas 1 e 2).

Exceto nas rações basais, na primeira fase, reduziu-se o nível de Pd (P disponível) de $0,46 \%$ para $0,34 \%$ e o de Ca de $0,96 \%$ para $0,80 \%$ e, na segunda fase, o nível de Pd de $0,40 \%$ para $0,30 \%$ e o de Ca de 0,87 para $0,70 \%$; a estas rações foram adicionados $500 \mathrm{FTU}$ de fitase $/ \mathrm{kg}$ de ração (Ronozyme ${ }^{\circledR}$ - P5000).

Avaliaram-se o consumo de ração, o ganho de peso, e a conversão alimentar corrigida como medidas de desempenho no período de 1 a 42 dias. Aos 42 dias de idade, foi 
Tabela 1 - Composições percentual e calculada das rações experimentais (1 a 21 dias de idade)

Table - Percentage and calculated compositions of the experimental diets (from 1 to 21 days of age)

\begin{tabular}{|c|c|c|c|}
\hline \multirow[t]{2}{*}{$\begin{array}{l}\text { Ingrediente (\%) } \\
\text { Ingredient }\end{array}$} & \multicolumn{3}{|c|}{$\begin{array}{l}\text { Ração experimental } \\
\text { Experimental diet }\end{array}$} \\
\hline & $\begin{array}{c}\text { Ração basal } \\
\text { Basal diet }\end{array}$ & $\begin{array}{c}19 \% \mathrm{~PB} \\
19 \% C P\end{array}$ & $\begin{array}{r}17 \% \text { PB } \\
17 \% C P\end{array}$ \\
\hline Milho grão (Corn) & 56,600 & 61,300 & 66,300 \\
\hline Farelo de soja (Soybean meal) & 35,700 & 30,200 & 24,800 \\
\hline Fosfato bicálcico & 1,900 & 1,280 & 1,310 \\
\hline \multicolumn{4}{|l|}{ Dicalcium phosphate } \\
\hline Óleo de soja (Soybean oil) & 3,220 & 2,830 & 2,310 \\
\hline Calcário calcítico (Limestone) & 1,000 & 1,060 & 1,090 \\
\hline Sal (Salt) & 0,500 & 0,500 & 0,500 \\
\hline L-Lys $\mathrm{HCl}$ (78\%) & 0,170 & 0,350 & 0,500 \\
\hline DL-Met & 0,230 & 0,280 & 0,330 \\
\hline L-Val & 0,000 & 0,100 & 0,200 \\
\hline L-Arg & 0,000 & 0,000 & 0,160 \\
\hline L-Thr & 0,000 & 0,000 & 0,080 \\
\hline L-Ile & 0,000 & 0,000 & 0,080 \\
\hline Premix vitamínico ${ }^{1}$ & 0,045 & 0,045 & 0,045 \\
\hline \multicolumn{4}{|l|}{ Vitamin premix } \\
\hline Premix mineral ${ }^{2}$ (Mineral premix) & 0,050 & 0,050 & 0,050 \\
\hline Cloreto de colina $(60 \%)$ & 0,050 & 0,050 & 0,050 \\
\hline \multicolumn{4}{|l|}{ Choline chloride } \\
\hline Salinomicina (12\%) (Salinomicin) & 0,021 & 0,021 & 0,021 \\
\hline Bacitracina de Zn (15\%) & 0,010 & 0,010 & 0,010 \\
\hline \multicolumn{4}{|l|}{ Zn bacitracin } \\
\hline Fitase (Phytase) & 0,000 & 0,010 & 0,010 \\
\hline Inerte (Inert) & 0,504 & 1,914 & 2,154 \\
\hline
\end{tabular}

Composição calculada

Calculated composition

\begin{tabular}{lrrr}
\hline EM (ME) (kcal/kg) & 3.000 & 3.000 & 3.000 \\
PB (CP) (\%) & 21,4 & 19,0 & 17,0 \\
P disponível (Available P) (\%) & 0,45 & 0,34 & 0,34 \\
Ca (\%) & 0,96 & 0,80 & 0,80 \\
K (\%) & 0,83 & 0,74 & 0,65 \\
Na (\%) & 0,23 & 0,23 & 0,23 \\
Cl (\%) & 0,32 & 0,33 & 0,33 \\
Balanço eletrolítico (mEq/kg) & 223 & 199 & 176 \\
Electrolytic balance & & & \\
Arg $\left.^{4} \%\right)$ & 1,32 & 1,17 & 1,17 \\
Ile $\left.{ }^{4} \%\right)$ & 0,82 & 0,73 & 0,72 \\
Lys $^{4}(\%)$ & 1,15 & 1,15 & 1,15 \\
Met + cys $^{4}$ (\%) & 0,81 & 0,81 & 0,82 \\
Thr $^{4}(\%)$ & 0,71 & 0,64 & 0,65 \\
Val $^{4}$ (\%) & 0,87 & 0,88 & 0,89 \\
AAE:AANE & $47: 53$ & $47: 53$ & $49: 51$ \\
\hline
\end{tabular}

${ }_{1}^{1}$ Fornecimento por kg de produto (Content per $\mathrm{kg}$ of product): $12.000 \mathrm{mg}$ vit. B2; 30.000 .000 Ul vit. A; 6.000 .000 UI vit D3; $6.000 \mathrm{mg}$ vit.B1; $12.000 \mathrm{mg}$ vit. B6; $60.000 \mathrm{mcg}$ vit. B12; $240 \mathrm{mg}$ biotina (biotin); $3.000 \mathrm{mg}$ ácido fólico (folic acid); $30.000 \mathrm{mg}$ ácido pantotênico (pantothenic acid); $8.000 \mathrm{mg}$ Vit. K3; $60.000 \mathrm{mg}$ vit. E.

2 Fornecimento por kg de produto (Content per $\mathrm{kg}$ of product): $110.000 \mathrm{mg} \mathrm{Zn}$; $96.00 \mathrm{mg} \mathrm{Fe} ; 20.000 \mathrm{mg} \mathrm{Cu} ; 156.000 \mathrm{mg} \mathrm{Mn} ; 1.400 \mathrm{mg} \mathrm{I}, 360 \mathrm{mg} \mathrm{Se}$.

3 O balanço eletrolítico das rações foram calculados segundo o número de Mongin (1981) (The electrolytic balance of the diets was calculated according to the number of Mongin, 1981) - $(\mathrm{Na}+\mathrm{K}-\mathrm{Cl})$.

${ }^{4}$ Aminoácidos digestíveis, calculado de acordo com as tabelas brasileiras para aves e suínos (Digestible amino acids, calculated in according to the Brazilian tables for chickens and swine) (Rostagno et al., 2000).

${ }^{5}$ Relação aminoácido essenciais (Relation of essential amino acid) (AAE) e não-essenciais (and non essential) (AANE). Os cálculos dos aminoácidos totais foram feitos de acordo com a tabela de composição química de alimentos do Centro Nacional de Pesquisa de Suínos e Aves (The calculations of the total amino acids were according to the table of chemical composition of feed of the National Center of Research of swine and birds) (Embrapa, 1991).
Tabela 2 - Composições percentual e calculada das rações experimentais (22 a 42 dias de idade)

Table 2 - Percentage and calculated compositions of the experimental (from 22 to 42 days of age)

\begin{tabular}{|c|c|c|c|}
\hline \multirow[t]{2}{*}{$\begin{array}{l}\text { Ingrediente (\%) } \\
\text { Ingredient }\end{array}$} & \multicolumn{3}{|c|}{$\begin{array}{l}\text { Ração experimental } \\
\text { Experimental diet }\end{array}$} \\
\hline & $\begin{array}{c}\text { Ração basal } \\
\text { Basal diet }\end{array}$ & $\begin{array}{c}19 \% \mathrm{~PB} \\
19 \% C P\end{array}$ & $\begin{array}{r}17 \% \mathrm{~PB} \\
17 \% C P\end{array}$ \\
\hline Milho grão (Corn) & 61,700 & 63,300 & 68,800 \\
\hline Farelo de soja (Soybean meal) & 30,530 & 27,620 & 22,200 \\
\hline Fosfato bicálcico & 1,580 & 1,100 & 1,170 \\
\hline \multicolumn{4}{|l|}{ Dicalcium phosphate } \\
\hline Óleo de soja (Soybean oil) & 3,740 & 3,880 & 3,160 \\
\hline Calcário calcítico (Limestone) & 1,000 & 0,880 & 0,940 \\
\hline Sal (Salt) & 0,480 & 0,480 & 0,480 \\
\hline L-Lys $\mathrm{HCl} 78 \%$ & 0,180 & 0,300 & 0,450 \\
\hline DL-Meti & 0,200 & 0,240 & 0,280 \\
\hline L-Val & 0,000 & 0,110 & 0,200 \\
\hline L-Arg & 0,000 & 0,050 & 0,210 \\
\hline L-Thr & 0,000 & 0,000 & 0,070 \\
\hline L-Ile & 0,000 & 0,020 & 0,120 \\
\hline Premix vitamínico ${ }^{1}$ & 0,035 & 0,035 & 0,035 \\
\hline \multicolumn{4}{|l|}{ Vitamin premix } \\
\hline Premix mineral (Mineral premix) ${ }^{2}$ & 0,050 & 0,050 & 0,050 \\
\hline Cloreto de colina $(60 \%)$ & 0,050 & 0,050 & 0,050 \\
\hline \multicolumn{4}{|l|}{ Choline chloride } \\
\hline Salinomicina $(12 \%)$ & 0,021 & 0,021 & 0,021 \\
\hline \multicolumn{4}{|l|}{ Salinomicin } \\
\hline $\begin{array}{l}\text { Bacitracina de Zn (15\%) } \\
\text { Zn bacitracin }\end{array}$ & 0,010 & 0,010 & 0,010 \\
\hline Inerte (Inert) & 0,424 & 1,844 & 1,744 \\
\hline Fitase (Phytase) & 0,000 & 0,010 & 0,010 \\
\hline
\end{tabular}

Composição calculada

Calculated composition

\begin{tabular}{lrrr}
\hline EM (ME) (kcal/kg) & 3.100 & 3.100 & 3.100 \\
PB (CP) (\%) & 19,3 & 18,0 & 16,0 \\
P disponível (Available P) (\%) & 0,40 & 0,30 & 0,30 \\
Ca (\%) & 0,87 & 0,70 & 0,70 \\
K (\%) & 0,75 & 0,70 & 0,61 \\
Na (\%) & 0,23 & 0,23 & 0,23 \\
Cl (\%) & 0,32 & 0,32 & 0,32 \\
Balanço eletrolítico (mEq/kg) & 201 & 188 & 165 \\
Electrolytic balance & & & \\
Lys $^{4}(\%)$ & 1,04 & 1,04 & 1,04 \\
Met+Cys $^{4}$ (\%) & 0,74 & 0,74 & 0,74 \\
Val $^{4}(\%)$ & 0,80 & 0,85 & 0,85 \\
Arg $^{4}(\%)$ & 1,18 & 1,15 & 1,15 \\
Thre $^{4}(\%)$ & 0,64 & 0,60 & 0,60 \\
Ile $^{4}(\%)$ & 0,74 & 0,71 & 0,71 \\
AAE:AANE $^{5}$ & $47: 53$ & $47: 53$ & $49: 51$ \\
\hline
\end{tabular}

${ }^{1}$ Fornecimento por kg de produto (Content per $k g$ of product): $12.000 \mathrm{mg}$ vit. B2 30.000 .000 UI vit. A; 6.000 .000 UI vit D3; $6.000 \mathrm{mg}$ vit.B1; $12.000 \mathrm{mg}$ vit. B6; $60.000 \mathrm{mcg}$ vit. B12; $240 \mathrm{mg}$ biotina (Biotin); $3.000 \mathrm{mg}$ ácido fólico (folic acid); 30.000 mg ácido pantotênico (Pantothenic acid); 8.000 mg Vit. K3 $60.000 \mathrm{mg}$ vit. E.

2 Fornecimento por kg de produto (Content per $\mathrm{kg}$ of product): $110.000 \mathrm{mg} \mathrm{Zn}$; $96.00 \mathrm{mg} \mathrm{Fe} ; 20.000 \mathrm{mg} \mathrm{Cu} ; 156.000 \mathrm{mg} \mathrm{Mn} ; 1.400 \mathrm{mg} \mathrm{I}, 360 \mathrm{mg} \mathrm{Se}$.

${ }^{3} \mathrm{O}$ balanço eletrolítico das rações foram calculados segundo o número de Mongin (1981) (The electrolytic balance of the diets was calculated according to the number of Mongin, 1981) - $(\mathrm{Na}+\mathrm{K}-\mathrm{Cl})$.

${ }^{4}$ Aminoácidos digestíveis, calculado de acordo com as tabelas brasileiras para aves e suínos (digestible amino acids, calculated in according to the Brazilian tables for chickens and swine) (Rostagno et al., 2000).

${ }^{5}$ Relação aminoácido essenciais (Relation essential amino acid) (AAE) e não essenciais (and non essentia) (AANE). Os cálculos dos aminoácidos totais foram feitos de acordo com a tabela de composição química de alimentos do Centro Nacional de Pesquisa de Suínos e Aves (The calculations of the total amino acids were according to the table of chemical composition of feed of the National Center of Research of swine and birds) (Embrapa, 1991). 
avaliado o rendimento de carcaça, peito, coxa+sobrecoxa e a porcentagem de gordura abdominal.

As análises estatísticas foram realizadas utilizando-se o software estatístico SISVAR descrito por Ferreira (2000) e, no caso de significância, aplicou-se o teste Scott-Knott a 5\% de probabilidade, para comparação das médias.

\section{Resultados e Discussão}

Observa-se que as aves que receberam ração com menores níveis de proteína (17\% PB na fase inicial e 16\% PB na fase de crescimento), em ambas as fases de criação, apresentaram o menor consumo $(\mathrm{P}<0,05)$ (Tabela 3). Segundo Diambra \& McCartney (1995), aves submetidas a rações com níveis reduzidos de proteína tendem a aumentar o consumo na tentativa de suprir possíveis deficiências em proteína e/ou aminoácidos. Este fato não foi observado neste estudo, possivelmente, em razão da suplementação com aminoácidos.

As aves que receberam dietas com 21,4 e 18\%PB; 21,4 e $16 \% \mathrm{~PB}$; e 19 e $16 \% \mathrm{~PB}$, respectivamente, na fases inicial e de crescimento, apresentaram consumo semelhante ao daquelas alimentadas com a dieta contendo 21,4 e 19,3\% PB, na primeira e segunda fases, respectivamente.

O desempenho das aves foi afetado negativamente $(\mathrm{P}<0,05)$ quando se avaliaram o ganho de peso e a conversão alimentar daquelas aves que receberam rações com níveis nutricionais reduzidos na fase inicial ( 1 a 21 dias) e na fase de crescimento (22 a 42 dias de idade), ou seja, os PN4 (19\% PB na fase 1+ 16\% PB na fase 2) e PN5 (17\% PB $+16 \% \mathrm{~PB})$, na primeira e segunda fases, respectivamente.

Observou-se que, ao fornecer uma ração basal com níveis nutricionais recomendados pela tabela brasileira (Rostagno et al., 2000), na primeira fase de criação, e rações com níveis reduzidos de PB (18 e/ou 16 \% de PB) na fase de crescimento (22 a 42 dias de idade), o desempenho foi semelhante $(\mathrm{P}>0,05)$ ao daquelas aves que receberam a ração basal nas duas fases de criação. Desta forma, pode-se inferir que as aves na fase inicial são mais sensíveis à redução de nutrientes, mesmo que a ração seja suplementada com enzima fitase e aminoácidos.

Estes resultados validam e confirmam os resultados obtidos por Silva (2004) e Nagata (2005b), que encontraram resultados positivos quando reduziram os níveis de nutrientes nas rações de frangos de corte na fase final de criação (22 a 42 dias de idade), devidamente suplementadas com aminoácidos e a enzima fitase.

Rostagno et al. (2002) constataram que a redução da PB para $18 \%$ piorou o desempenho das aves e as rações contendo 19\% de PB precisam ser suplementadas com glicina para proporcionar desempenho semelhante ao da ração controle, com $22 \%$ de PB na fase inicial. Segundo os autores, a exigência de glicina+serina para aves de corte de 8 a 21 dias alimentadas com rações contendo 19\% de PB seria igual ou superior a 2,108\%. Entretanto, o nível nutricional de glicina+serina da ração inicial com $19 \%$ de PB utilizada no PN4 foi de 1,8\%, estando abaixo do indicado por aqueles autores, fato que pode ter influenciado o baixo desempenho das aves.

Os motivos para o baixo desempenho de aves alimentadas com rações contendo baixo nível protéico ainda não estão totalmente esclarecidos, no entanto, existem algumas hipóteses. Com a significativa redução do teor de proteína da ração, a disponibilidade de aminoácidos na forma de di e tripeptídeos pode ter sido reduzida. Em humanos adultos, aproximadamente 33\% da proteína é absorvida como aminoácidos e o restante (67\%), como pequenos peptídeos (Zaloga, 1990). Desta forma, a redução da proteína da dieta pode limitar a disponibilidade de peptídeos para síntese de proteínas. Também existem evi-

Tabela 3 - Efeito de planos nutricionais (PN) com níveis reduzidos de PB, Ca e P disponível com aminoácidos e fitase sobre o desempenho de frangos de corte da linhagem Cobb no período de 1 a 42 dias de idade

Table 3 - Effect of nutritional plans (NP) with reduced levels of CP, Ca and available $P$ with amino acids and phytase on performance of broiler chickens of Cobb strain from 1 to 42 days of age

\begin{tabular}{|c|c|c|c|}
\hline \multirow[t]{2}{*}{$\begin{array}{l}\text { Plano nutricional } \\
\text { Nutritional plan }\end{array}$} & \multicolumn{3}{|c|}{$\begin{array}{l}1 \text { a } 42 \text { dias de idade } \\
1 \text { to } 42 \text { days of age }\end{array}$} \\
\hline & $\begin{array}{c}\text { Consumo ração (g/ave) } \\
\text { Feed intake }\end{array}$ & $\begin{array}{c}\text { Ganho de peso (g/ave) } \\
\text { Weight gain }\end{array}$ & $\begin{array}{c}\text { Conversão alimentar }(\mathrm{g} / \mathrm{g}) \\
\text { Feed conversion }\end{array}$ \\
\hline PN1 (NP1) - 21,4\% + 19,3\% PB (CP) & $4.877 \mathrm{a}$ & $2.839 \mathrm{a}$ & $1,718 \mathrm{a}$ \\
\hline PN2 (NP2) - 21,4\% + 18\% PB (CP) & $4.934 a$ & $2.892 \mathrm{a}$ & $1,707 \mathrm{a}$ \\
\hline PN3 (NP3) - 21,4\% + 16\% PB (CP) & $4.935 a$ & $2.808 \mathrm{a}$ & $1,722 \mathrm{a}$ \\
\hline PN4 (NP4) $-19 \%+16 \%$ PB (CP) & $4.852 \mathrm{a}$ & $2.737 b$ & $1,772 b$ \\
\hline PN5 (NP5) - $17 \%+16 \%$ PB (CP) & $4.658 b$ & $2.655 b$ & $1,754 b$ \\
\hline CV(\%) & 2,00 & 2,62 & 2,35 \\
\hline
\end{tabular}

Médias, na coluna, seguidas por diferentes letras diferem $(P<0,05)$ pelo teste Scoot-Knott.

Means, within a column, followed by different letters differ $(P<0.05)$ by Scoot-Knott test. 
dências de que a absorção de aminoácidos sintéticos é mais rápida que a absorção de aminoácidos presentes na proteína dos alimentos (Partridge et al., 1985). O ganho de peso inferior obtido pelas aves que consumiram as rações dos PN4 (19 e 16\% de PB nas fases inicial e de crescimento, respectivamente) e PN5 (17 e 16\% de PB nas fases inicial e de crescimento, respectivamente) pode ser atribuído à necessidade de inclusão de maior quantidade de aminoácidos sintéticos nessas rações, para atender às exigências em aminoácidos das aves, o que pode ter resultado em diferenças nas taxas de absorção, pois, segundo Pinchasov et al. (1990), é possível que diferentes taxas de absorção de aminoácidos e peptídeos resultem em um “pool” sub-ótimo de aminoácidos nos sítios específicos de síntese protéica, insuficiente para sustentar alta taxa de crescimento.

Para ocorrer síntese de proteínas, deve haver disponibilidade de aminoácidos essenciais (AAE) e não-essenciais (AANE) (no meio celular todos os aminoácidos são considerados essenciais) (Bedford \& Summers, 1985), além de variação na proporção entre AAE e AANE. Observa-se que as rações adotadas nesta pesquisa apresentaram relações AAE:AANE diferentes da preconizada por Bedfors \& Summers (1985), de 55:45 (Tabelas 1 e 2). Possivelmente, este não foi o motivo para o baixo desempenho das aves que consumiram ração com níveis reduzidos de proteína bruta, pois a ração basal também não apresentou a relação ideal preconizada por este autor.

Em razão de o farelo de soja ser rico em colina, a redução deste ingrediente na dieta de menor proteína requer a suplementação desse nutriente (Schutte, 1999). O farelo de soja também é rico em potássio, e sua redução nas dietas pode comprometer o balanço eletrolítico. Murakami (2000) recomenda o balanço eletrolítico entre 150 e 350 mEq/ kg de ração para o máximo desempenho das aves, ao passo que Leeson \& Summers (2001) consideram o valor de 250 $\mathrm{mEq} / \mathrm{kg}$ adequado para o bom desenvolvimento das aves. As rações utilizadas neste experimento apresentaram o balanço eletrolítico na faixa de 165 a $223 \mathrm{mEq} / \mathrm{kg}$. Apesar de as rações não terem sido isopotássicas, o balanço eletrolítico está dentro do recomendado pela literatura, indicando que esta não foi a causa da queda do desempenho, quando as aves consumiram ração com níveis reduzidos de PB.

Os rendimentos de carcaça e peito não foram influenciados $(\mathrm{P}>0,05)$ pelos planos nutricionais utilizados. No entanto, o rendimento de coxa + sobre coxa foi inferior $(\mathrm{P}<0,05)$ quando os níveis de nutrientes foram reduzidos na ração, independentemente da fase de criação e da suplementação com fitase e aminoácidos (Tabela 4). Observa-se ainda que os valores de gordura abdominal das aves alimentadas com a ração basal na fase inicial e a ração com 18\% de PB na fase de crescimento foram semelhantes aos daquelas que receberam ração basal com níveis nutricionais normais, durante toda a fase de criação (PN1), demonstrando que, apesar do menor rendimento de coxa + sobre coxa, é possível reduzir o nível de nutrientes na fase final de criação e obter resultados satisfatórios.

Todavia, ficou evidente que a redução do nível protéico para 16\% de PB na segunda fase (22 a 42 dias), independentemente do nível utilizado na primeira fase (1 a 21 dias de idade), aumentou $(\mathrm{P}<0,05)$ o teor de gordura abdominal. Este resultado pode estar associado à maior inclusão de aminoácidos sintéticos nas rações com 16\% de PB.

O excesso de deposição de gordura na carcaça é prejudicial para a produção de frango de corte, pois a gordura é vista de modo desfavorável pelo consumidor e representa perda no rendimento se for removida durante a industrialização (Leenstra, 1986).

Tabela 4 - Efeito de planos nutricionais (PN) com níveis reduzidos de PB, Ca e P disponível com aminoácidos e fitase sobre os rendimentos de carcaça, peito e coxa + sobre-coxa e a porcentagem de gordura abdominal de frangos de corte da linhagem Cobb aos 42 dias de idade

Table 4 - Effect of nutritional plans (NP) with reduced levels of CP, Ca and available $P$ with amino acids and phytase on yields of carcass, breast and thigh + drumstick and abdominal fat percentage of broiler chickens of Cobb strain in the period from 1 to 42 days of age

Plano nutricional

Nutritional plan

Rendimento (\%)

Yield

\begin{tabular}{cccc}
$\begin{array}{c}\text { Carcaça } \\
\text { Carcass }\end{array}$ & $\begin{array}{c}\text { Peito } \\
\text { Breast }\end{array}$ & $\begin{array}{c}\text { Coxa }+ \text { sobre-coxa } \\
\text { Thigh }+ \text { drumstick }\end{array}$ & $\begin{array}{c}\text { Gordura abdominal } \\
\text { Abdominal fat }\end{array}$ \\
\hline $77,07 \mathrm{a}$ & $33,48 \mathrm{a}$ & $30,20 \mathrm{a}$ & $1,52 \mathrm{c}$ \\
$76,48 \mathrm{a}$ & $34,22 \mathrm{a}$ & $28,71 \mathrm{~b}$ & $1,70 \mathrm{c}$ \\
$76,00 \mathrm{a}$ & $34,41 \mathrm{a}$ & $28,79 \mathrm{~b}$ & $2,22 \mathrm{~b}$ \\
$76,90 \mathrm{a}$ & $33,72 \mathrm{a}$ & $28,83 \mathrm{~b}$ & $2,68 \mathrm{a}$ \\
$76,09 \mathrm{a}$ & $33,31 \mathrm{a}$ & $29,26 \mathrm{~b}$ & $2,32 \mathrm{~b}$ \\
1,16 & 2,76 & 3,05 & 16,00 \\
\hline
\end{tabular}

Médias, na coluna, seguidas por diferentes letras diferem $(P<0,05)$ pelo teste Scoot-Knott. Means, within a column, followed by different letters differ $(P<0.05)$ by Scoot-Knott test. 
Sklan \& Plavnik (2002) citam que o consumo de rações com baixo conteúdo protéico acarreta aumento na deposição de gordura nos tecidos, em razão da incapacidade da ave em utilizar energia para a deposição de proteína. A possível deficiência de algum aminoácido pode ter limitado a síntese protéica e, desta forma, os aminoácidos ficaram disponíveis para a síntese de gordura.

Segundo Fischer (1994), em condições de deficiência nutricional, principalmente de aminoácidos essenciais, a musculatura do peito é um dos parâmetros afetados. Neste trabalho, a porcentagem de peito não foi influenciada pelos níveis de PB da dieta, indicando que, mesmo nos menores níveis protéicos, houve fornecimento satisfatório de aminoácidos essenciais. Resultados semelhantes foram encontrados por Sabino et al. (2004), em estudo com níveis reduzidos de $\mathrm{PB}(15,17,19,21$ e 23\%). Esses autores relataram que a porcentagem de peito não foi influenciada pelos níveis protéicos da dieta.

\section{Conclusões}

É possível reduzir o nível protéico da ração na fase de crescimento (22 a 42 dias de idade) até $16 \%$ de PB, suplementada com aminoácidos e fitase, desde que a ração da fase inicial (1 a 21 dias de idade) seja formulada com níveis nutricionais recomendados pela literatura brasileira.

\section{Literatura Citada}

BEDFORD, M.R.; SUMMERS, J.D. Influence of the ratio of essential to non essential amino acids on performance and carcass composition of the broiler chick. British Poultry Science, v.26, p.483-491, 1985.

BREGENDAHL, K.; SELL, J.L.; ZIMMERMAN, D.R. Effect of low-protein diets on growth performance and body composition of broiler chicks. Poultry Science, v.81, p.1156-1167, 2002.

COSTA, F.G.P.; ROSTAGNO, H.S.; ALBINO, L.F.T. et al. Níveis dietéticos de proteína bruta para frangos de corte de 1 a 21 e 22 a 42 dias de idade. Revista Brasileira de Zootecnia, v.30, p.1498-1505, 2001.

DIAMBRA, O. H.; McCARTNEY, M.G. The effect of low protein finisher diets on broiler males performance and abdominal fat. Poultry Science, v.64, p.2013-2015, 1995.

EMPRESA BRASILEIRA DE PESQUISA E AGROPECUÁRIA EMBRAPA. Tabelas de composição química e valores energéticos de alimentos para suínos e aves. 3.ed. Concórdia: Centro Nacional de Pesquisa de Suínos e Aves, 1991. 97p. (Documentos, 19).

FERREIRA, D.F. Análises estatísticas por meio do SISVAR para Windows versão 4. 0. In: REUNIÃO ANUAL DA REGIÃO BRASILEIRA DA SOCIEDADE INTERNACIONAL DE BIOMETRIA, 45., 2000, São Carlos. Anais... São Carlos: Universidade Federal de São Carlos, 2000. p.255-258.

FISCHER, C. Use of amino acids to improve carcass quality of broilers. Feed Mix, v.2, p.17-20, 1994.

HAN, Y.; SUZUKY, H.; PARSONS, C.M. et al. Amino acid fortification of a low-protein corn and soybean meal diets for chicks. Poultry Science, v.71, n.7, p.1168-1178, 1992.
LAN, G.Q.; ABDULLAH, N.; JALALUDIN, S. et al. Efficacy of supplementation of a phytase-producing bacterial culture on the performance and nutrient use of broiler chickens fed corn-soybean meal diets. Poultry Science, v.81, n.10, p.1522-1532, 2002.

LEENSTRA, F.R. Effect of age, sex, genotype and environment on fat deposition in broiler chickens: a review. World's Poultry Science Journal, v.42, p.12-25, 1986.

LEESON, S.; SUMMERS, J.D. Scott's nutrition of the chicken. 4.ed. Ontario: University Books, 2001. 591p.

MONGIN, P. Recent advances in dietary anion-cation balance: application in poultry. Procedure Nutrition Society, v.40, p.285-294, 1981.

MURAKAMI, A.E. Balanço eletrolítico da dieta e sua influência sobre o desenvolvimento dos ossos de frangos. In: CONFERÊNCIA APINCO DE CIÊNCIA E TECNOLOGIA AVÍCOLAS, 2000, Campinas. Palestras... Campinas: Fundação APINCO de Ciência e Tecnologia Avícolas, 2000. p.33-61.

NAGATA, A.K.; RODRIGUES, P.B.; RODRIGUES, K.F. et al. Energia metabolizável e proteína ideal para frangos de corte de 1 a 21 dias de idade, utilizando aminoácidos sintéticos e fitase. Revista Brasileira de Ciência Avícola, v.7, p.85, 2005a (supl.).

NAGATA, A.K.; RODRIGUES, P.B.; RODRIGUES, K.F. Níveis de energia metabolizável e proteína bruta em rações suplementadas com fitase e aminoácidos sintéticos para frangos de corte no período de 22 a 42 dias de idade. In: REUNIÃO ANUAL DA SOCIEDADE BRASILEIRA DE ZOOTECNIA, 42., 2005, Goiânia - GO. Anais... Goiânia: SBZ, 2005b. (CD-ROM).

PARTRIDGE, I.G.; LOW, A.G.; KEAL, H.D. A note on the effect of feeding frequency on nitrogen use in growing boars given diets with varying levels of free lysine. Animal Production, v.40, n.2, p.375-377, 1985.

PINCHASOV, Y.; MENDONÇA, C.X.; JENSEN, L.S. Broiler chick response to low protein diets supplemented with synthetic amino acids. Poultry Science, v.69, p.1950-1955, 1990.

ROSTAGNO, H.S.; ALBINO, L.F.T.; DONZELE, J.L. et al. Tabelas brasileiras para aves e suínos: composição de alimentos e exigências nutricionais. 2.ed. Viçosa, MG: Universidade Federal de Viçosa, 2000. 141p.

ROSTAGNO, H.S.; VARGAS JR., J.G.; ALBINO, L.F.T. et al. Níveis de proteína e aminoácidos em rações de pinto de corte. Revista Brasileira de Ciência Avícola, v.4, p.49, 2002 (supl.).

RUTHERFURD, S.M.; CHUNG, T.K.; MOREL, P.C.H. et al. Effect of microbial phytase on ileal digestibility of phytase phosphorus, total phosphorus, and amino acids in a low-phosphorus diet for broilers. Poultry Science, v.83, n.1, p.61-68, 2004.

SABINO, H.F.; SAKOMURA, N.K.; NEME, R. et al. Níveis protéicos na ração de frangos de corte na fase de crescimento. Pesquisa Agropecuária Brasileira, v.39, n.5 p.407-417, 2004.

SCHUTTE, J.B.; SMINK, W. Requirement of young broiler chicks for glycine+serine. Archive fur Gerflügelkunde, v.61, n.1, p.43-47, 1999.

SILVA, Y.L. Redução dos níveis de proteína e fósforo em rações com fitase para frangos de corte: desempenho, digestibilidade e excreção de nutrientes. Lavras: Universidade Federal de Lavras, 2004. 201p. Tese (Doutorado em Zootecnia) - Universidade Federal de Lavras, 2004.

SKLAN, D.; PLAVNIK, I. Interactions between dietary crude protein and essential amino acid intake on performance in broilers. British Poultry Science, v.43, p.442-449, 2002.

VIVEIROS, A.; BRENES, A.; ARIJA, I.; CENTENO, C. effects of microbial phytase supplementation on mineral utilization and serum enzyme activities in broiler chicks fed different levels of phosphorus. Poultry Science, v.81, n.8, p.1172-1183, 2002.

ZALOGA, G.P. Physiologic effects of peptide-based enteral formulas. Nutrition Clinical Practical, v.5, n.6, p.231-237, 1990.

Recebido: 3/4/2006 Aprovado: 15/5/2007 